\title{
Toxicity of Oxazolidinone Linezolid on Pathogenic Microorganism Listeria ivanovii
}

\author{
Neeta Surve \\ Applied Microbiology Laboratory, Department of Life Sciences \\ University of Mumbai, Vidyanagari, Santacruz (E) \\ Mumbai 400098, India \\ Tel: 91-966-581-1036 E-mail: taneesurve@gmail.com \\ Uttamkumar Bagde (Corresponding author) \\ Applied Microbiology Laboratory, Department of Life Sciences \\ University of Mumbai, Vidyanagari, Santacruz (E) \\ Mumbai 400098, India \\ Tel: 91-982-168-1672Ｅ-mail: bagdeu@yahoo.com
}

Received: June 9, 2011 Accepted: June 22, 2011 doi:10.5539/ijb.v3n4p72

\begin{abstract}
Oxazolidinone, a new class of antimicrobial agents is active against various Gram-positive bacteria, including methicillin-resistant Staphylococcus aureus (MRSA), Staphylococcus epidermidis (MRSE), penicillin-resistant Streptococcus pneumoniae (PRSP) and vancomycin-resistant Enterococci (VRE). Sensitivity of Oxazolidinone Linezolid was studied against pathogenic microorganism Listeria ivanovii and Minimum Inhibitory Concentration (MIC) determined by broth dilution method and Hi-Comb method was $10 \mu \mathrm{g} / \mathrm{ml}$. Morphological alterations on Listeria ivanovii cell surface were seen by Scanning Electron Microscopy (SEM) after treatment with Linezolid. Inhibition on the activity of dehydrogenases of organism by Linezolid was also studied in the present study.
\end{abstract}

Keywords: Linezolid, Listeria ivanovii, Scanning Electron Microscopy (SEM), Dehydrogenases, Hi-Comb Method, Minimum Inhibitory Concentration (MIC)

\section{Introduction}

Listeria monocytogenes has been found in number of food-borne disease outbreaks from past decade and several sporadic episodes of Listeria illness (Farber and Peterkin 1991). Apart from Listeria monocytogenes, Listeria ivanovii is only other Listeria sp which is considered to be pathogenic. They both invade host cells, replicate in the cytosol after phagosomal escape and spread from cell to cell by polymerizing actin (Vazquez-Boland et al., 2001). L. ivanovii has been reported to infect animals, causing abortions, neonatal sepsis and enteritis (Cooper et al., 1973; Seeliger et al., 1986; Seeliger et al., 1984), human infections are very rare. This organism has also been isolated from healthy animals, human carriers and the environment (Seeliger et al., 1986; Seeliger et al., 1984).

Guillet et al. (2010) studied two species of Listeria which were pathogenic and infected both humans and animals. They found that $L$. monocytogenes infects humans and animals and L. ivanovii infects ruminants only and it was associated with gastroenteritis and bacteremia in man. According to this recent study, it was shown that $L$. ivanovii was an enteric opportunistic human pathogen. The pathogenic changes associated with $L$. ivanovii in humans appear similar to those in ruminants, i.e., fetoplacental infections and septicemia (often accompanied by enteritis). Lack of central nervous system involvement could be a general characteristic of $L$. ivanovii infection regardless of host species (Seeliger et al., 1986).

In present investigation, sensitivity of L. ivanovii against Oxazolidinone Linezolid was studied by broth dilution method and Hi-Comb method (Hi-media) and MIC was determined. Morphological alterations on the cell 
surface of $L$. ivanovii were studied after treatment with Linezolid by Scanning Electron Microscope (SEM). Emphasis was also given on inhibition of dehydrogenases enzymes of organism by the antibiotic.

\section{Materials and methods}

\subsection{Organisms, Culture Media and Antibiotic}

L. ivanovii ATCC 19119 was obtained from Hi-media, India, for the present study. Organism was grown at $37{ }^{\circ} \mathrm{C}$ for 18 hours in Nutrient broth medium (Hi-media, India) and maintained at $5{ }^{\circ} \mathrm{C}$. Linezolid powder was gifted by Glenmark Pharmaceuticals Ltd., India for experimental purpose.

\subsection{Determination of MIC}

Minimum Inhibitory Concentration (MIC) of Linezolid against pathogenic microorganism L. ivanovii was determined by Broth dilution method (NCCLS 2001) and by Hi-Comb (Hi-media, India) method (CLSI 2008). In Broth dilution method, different concentrations of antibacterial agents were prepared. Inoculums were adjusted to 0.5 Macfarland turbidity standards and an aliquot of $0.1 \mathrm{ml}$ of inoculums was added to each tube of dilution. The tubes were incubated at $37^{\circ} \mathrm{C}$ overnight. MIC was read visually following 24 hours of incubation and was defined as the lowest concentration that produced no visible turbidity (NCCLS 2001).

In Hi-Comb method, at least 4 to 5 well isolated colonies of same morphological type from agar plate were touched with a wire loop and growth was transferred to tube containing $5 \mathrm{ml}$ of broth. Turbidity was compared with 0.5 Macfarland standards and adjusted with sterile saline or broth if required. Organism was spread on agar plates by spread plate method and Hi-Comb strip was placed on medium in sterile condition. Plate was incubated for 24 hours at $37^{\circ} \mathrm{C}$ and zone of inhibition was observed. According to Hi-Comb MIC test, MIC value is the value at which the zone converges on the comb-like projections of the strips and not at the handle and zone of inhibition below the lowest concentration is to be considered (CLSI 2008).

\subsection{Effect of Linezolid on morphology of L. ivanovii}

After determination of MIC, surface morphology was studied by SEM on Quanta 200 ESEM system (Icon Analytical Equipment Pvt. Ltd., India). Specified concentration of Linezolid (10 $\mu \mathrm{g} / \mathrm{ml})$ was added to culture in the logarithmic phase of growth ( 12 hour culture) at $37^{\circ} \mathrm{C}$. SEM was done after different incubation time period, $3 \mathrm{hrs}, 6 \mathrm{hrs}$ and $24 \mathrm{hrs}$ with Linezolid. Treated and untreated cells after incubation were washed by centrifugation in $0.9 \% \mathrm{NaCl}$ and fixed in $2 \%$ glutaraldehyde in $0.1 \mathrm{M}$ cacodylate buffer (pH 7.2) and images were taken by SEM (Klainer and Perkins 1974).

\subsection{Effect of Linezolid on Dehydrogenases activity}

Inhibition of Linezolid on dehydrogenase enzymes activity of $L$. ivanovii was studied by the procedure followed by Guha and Mookerjee (1979). After the cells grown for $48 \mathrm{hrs}$ at $37^{\circ} \mathrm{C}$, they were used as samples. According to the procedure, chloramphenicol was added to disrupt cell wall and MIC concentration of Linezolid was added. 0.005 M Substrates of TCA cycle, $\alpha$-Ketoglutaric acid, Succinic acid, Isocitric acid and Glutamic acid was added to each tube. $0.5 \mathrm{M}$ Potassium phosphate buffer at $\mathrm{pH}$ 7.0, $0.3 \mathrm{M} \mathrm{MgCl}_{2}$ and Triphenyl Tetrazolium Chloride solutions $(9 \mathrm{mg} / \mathrm{ml})$ were finally added and OD values of the control tubes and percentage inhibition of the activity of enzymes was calculated.

\section{Results}

In present investigation, MIC of Listeria ivanovii against oxazolidinone linezolid was determined by broth dilution method and Hi-Comb method and was found to be $10 \mu \mathrm{g} / \mathrm{ml}$. The inhibition in the growth of L. ivanovii was read visually by broth dilution method and in Hi-Comb method, zone of inhibition was seen after 24 hour incubation (figure 1).

Morphological alterations on cell surface of L. ivanovii after treating with Linezolid for 3 hours, 6 hours and 24 hours are shown in Figures 2 and 3. Images of control organism which was not treated by Linezolid (figure 2) and test organism treated by Linezolid $(10 \mu \mathrm{g} / \mathrm{ml}$ ) (figures 3a-c) were taken by SEM. Normal control cells were seen as rod shaped while cells treated with Linezolid showed changes at different time intervals. The effect of linezolid $(10 \mu \mathrm{g} / \mathrm{ml})$ on L. ivanovii strain resulted in elongation of cells after 3 hours (figure 3a); formation of spheroplasts after 6 hours (figure $3 \mathrm{~b}$ ) and ultimately spheroplasts and small broken pieces of cells were seen after 24 hours incubation time period (figure $3 \mathrm{c}$ ).

Inhibition of dehydrogenase enzymes was seen after exposing them to Linezolid. Percentage inhibition of dehydrogenases activity was Glutamic $65 \%$, Succinic $50 \%$, $\alpha$-ketoglutaric $69 \%$, and Isocitric dehydrogenases $62 \%$ (table 1). The percentage inhibition of the activity of enzymes was calculated by comparing the $\mathrm{O}$. D. values of the control tubes and the tubes containing Linezolid. 


\section{Discussion}

During the past decade, emergence of bacterial resistance to antibiotics has posed serious concern to medical professionals. Oxazolidinones represent a new synthetic class of antibacterial agents with activity against gram-positive organisms (Brickner et al., 1996). The antimicrobial activities of the oxazolidinones were first described by scientists at E. I. Dupont de Nemours and Co., Inc (Daly et al., 1988; Slee et al., 1987). The Oxazolidinones Linezolid and Eperezolid have shown activity against methicillin-resistant Staphylococcus aureus, penicillin-resistant Streptococcus pneumoniae and vancomycin-resistant Enterococcus faecium (Ford et al., 1996; Jones et al., 1996; Kaatz and Seo 1996; Mason et al., 1996; Zurenko et al., 1996).

Swaney et al. (1998) demonstrated that Oxazolidinone Linezolid inhibit the formation of the initiation complex in bacterial translation systems by preventing formation of the N-formyl-methionyl-tRNA-ribosome-mRNA ternary complex. Lin et al. (1997) concluded that the Oxazolidinone Eperezolid inhibited protein synthesis by binding to the 50S ribosomal subunit at a site close to the site(s) to which chloramphenicol and lincomycin bind but that the oxazolidinones were mechanistically distinct from these two antibiotics. Cui et al. (2005) synthesized a series of oxazolidinones and compared their activities against a panel of gram-positive bacteria with linezolid.

Troxler et al. (2000) described a database on susceptibility of Listeria species strains to a wide range of antibiotics. Scortti et al. (2006) studied fosfomycin susceptibility against $L$. monocytogenes and found resistant in vitro, although they are in fact susceptible to the antibiotics during infection. In present study, Linezolid susceptibility was studied against $L$. ivanovii and MIC determined by both broth dilution method and Hi-Comb method was found to be $10 \mu \mathrm{g} / \mathrm{ml}$. Hi-Comb MIC test (Himedia) was used for cross checking MIC of the antimicrobial and was found to be $10 \mu \mathrm{g} / \mathrm{ml}$. Menezes et al. (2008) also used Hi-Comb test for determination of MIC on S. hemolyticus and S. aureus against vancomycin. Hi-comb test is useful for determining the antimicrobial susceptibility of aerobes and anaerobes, non-fastidious and fastidious organisms. Surve and Bagde (2010b) studied susceptibility of Streptococcus agalactiae against methicillin with the help of Hi-Comb MIC test and determined its MIC.

Morphological changes observed by SEM in the present study are in substantial agreement with the previous reports of surface disruption of antibiotics treated organisms (Klainer and Perkins 1974; Klainer and Perkins 1972). Formation of spheroplast represents a final common pathway of drug induced injury at many sites within or on bacterial cells. The present study demonstrates that antimicrobial agent whose site of action is thought to be intracellular may cause morphological alterations which are similar to those induced by cell-wall active drugs.

Surve and Bagde (2009; 2010a; 2010b) reported inhibition effects of silver, arsenic and methicillin on dehydrogenase activity of pathogenic microorganisms. Effect of trivalent and hexavalent chromium on a freshwater fish Anabes scandens was studied by Venugopal and Reddy (1992) and found that activities of lactate dehydrogenase, malate dehydrogenase and isocitrate dehydrogenase were inhibited. In present investigation, inhibition of four dehydrogenases involved in the TCA cycle, glutamic, succinic, $\alpha$-ketoglutaric, and isocitric dehydrogenases was found to a greater extent, when bacterial cells were exposed to linezolid.

\section{References}

Brickner, S. J., Hutchinson, D. K., Barnachyn, M. R., Manninen, P. R., Ulanowiez, D. A., Garmon, S. A., et al. (1996). Synthesis and antibacterial activity of U-100592 and U-100766, two oxazolidinone antibacterial agents for the potential treatment of multidrug-resistant gram-positive bacterial infections. J. Med. Chem., 39(3): 673-679. http://dx.doi.org/10.1021/jm9509556

Clinical and Laboratory Standards Institute. (2008). Performance Standards for Antimicrobial Susceptibility Testing. CLSI, 28(1).

Cooper, R. F., Dennis, S. M., \& McMahon, K. J. (1973). Characterization of Listeria monocytogenes serotype 5. Am. J. Vet. Res., 34: 1093-1099.

Cui, Y., Dang, Y., Yang, Y., \& Ji, R. (2005). Synthesis of novel oxazolidinone derivatives for antibacterial investigation. Current Sience, 89(3): 531-534. http://cat.inist.fr/?aModele=afficheN\&cpsidt=17421022

Daly, J. S., Eliopoulos, G. M., Wiley, S., \& Moellering, Jr., R. C. (1988). Mechanism of action and in vitro and in vivo activities of S-6123, a new oxazolidinone compound. Antimicrob. Agents Chemother, 32(9): 1341-1346. http://aac.asm.org/cgi/content/abstract/32/9/1341

Farber, J. M., \& Peterkin, P. I. (1991). Listeria monocytogenes, a food-borne pathogen. Microbiol Rev., 55: 476-511. http://www.ncbi.nlm.nih.gov/pubmed/1943998 
Ford, C. W., Hamet, J. C., Wilson, D. M., Moerman, J. K., Stapert, D., Yancey, R. J., Jr., et al. (1996). In vivo activities of U-100592 and U-100766, novel oxazolidinone antimicrobial agents, against experimental bacterial infections. Antimicrob. Agents Chemother., 40(6): 1508-1513. http://www.ncbi.nlm.nih.gov/pubmed/8726028

Guha, C., \& Mookerjee, A. (1979). Effect of Nickel on macromolecular synthesis in Escherichia coli K12. The Nucleus, 22(1): 45-47.

Guillet, C., Join-Lambert, O., Le Monnier, A., Leclercq, A., Mechai, F., Mamzer-Bruneel, M. F., et al. (2010). Human Listeriosis caused by Listeria ivanovii. EID Journal Home, 16(1): 136.htm.

Jones, R. N., Johnson, D. M. \& Erwin, M. E. (1996). In vitro antimicrobial activities and spectra of U-100592 and U-100766, two novel fluorinated oxazolidinones. Antimicrob. Agents Chemother., 40(3): 720-726. http://aac.asm.org/cgi/content/abstract/40/3/720

Kaatz, G. W., \& Seo, S. M. (1996). In vitro activities of oxazolidinone compounds U-100592 and U-100766 against Staphylococcus aureus and Staphylococcus epidermidis. Antimicrob. Agents Chemother., 40(3): 799-801. http://www.ncbi.nlm.nih.gov/pubmed/8851617

Klainer, A. S., \& Perkins, R. L. (1972). Surface Manifestations of Antibiotic-Induced alterations in protein synthesis in bacterial cells. Antimicrob. Agents Chemother., 1(2): 164-170. http://www.ncbi.nlm.nih.gov/pmc/articles/PMC444186/pdf/aac00356-0080.pdf

Klainer, A. S., \& Perkins, R. L. (1974). Effect of the inhibition of protein synthesis on Escherichia coli cell envelope. Antimicrob. Agents. Chemother., 6(2): 216-224. http://www.ncbi.nlm.nih.gov/pmc/articles/PMC444629/pdf/aac00338-0100.pdf

Lin, A. H., Murray, R. W., Vidmar, T. J., \& Marotti, K. R. (1997). The oxazolidinone eperezolid binds to the 50S Ribosomal Subunit and competes with binding of chloramphenicol and lincomycin. Antimicrob. Agents Chemother., 41(10): 2127-2131. http://aac.asm.org/cgi/content/abstract/41/10/2127

Mason, E. O., Lamberth, L. B., \& Kaplan, S. L. (1996). In vitro activities of oxazolidinones U-100592 and U-100766 against penicillin-resistant and cephalosporin-resistant strains of Streptococcus pneumoniae. Antimicrob. Agents Chemother., 40(4): 1039-1040. http://aac.asm.org/cgi/content/abstract/40/4/1039

Menezes, G. A., Harish, B. N., Sujatha, S., Vinothini, K. \& Parija, S. C. (2008). Emergence of vancomycin-intermediate Staphylococcus species in southern India. J. Medical. Microb., 911-912. http://jmm.sgmjournals.org/content/57/7/911.full

NCCLS. (2001). National Committee for Clinical Laboratory Standards. Methods for dilution antimicrobial susceptibility tests for bacteria that grow aerobically. Approved standard M7-A5, vol. 20. National Committee for Clinical Laboratory Standards, Wayne, Pa.

Scortti, M., Lacharme-Lora, L., Wagner, M., Chico-Calero, I., Losito, P., \& Vazquez-Boland, J. A. (2006). Coexpression of virulence and fosfomycin susceptibility in Listeria: molecular basis of an antimicrobial in vitro-in vivo paradox. Nat. Med., 12: 515-517. http://dx.doi.org/10.1038/nm1396

Seeliger, H. P. R., Jones, D. (1986). Genus Listeria Pirie, $383^{\mathrm{AL}}$, p. 1235-1245. In P. H. A. Sneath, N. S. Mair, M. E. Sharpe and J. G. Holt (ed.), Bergeys manual of systematic bacteriology, vol. 2. The Williams and Wilkins Co., Baltimore. 1986.

Seeliger, H. P. R., Rocourt, J., Schrettenbrenner, A., Grimont, P. A. D., \& Jones, D. (1984). Listeria ivanovii sp. nov. Int. J. Syst. Bacteriol., 34: 336-337. http://dx.doi.org/10.1099/00207713-34-3-336

Slee, A. M., Wuonola, M. A., McRipley, R. J., Zajac, I., Zawada, M. J., Bartholomew, P. T., et al. (1987). Oxazolidinones, a new class of synthetic antibacterial agents: in vitro and in vivo activities of DuP105 and DuP721. Antimicrob. Agents Chemother., 31(11): 1791-1797. http://aac.asm.org/cgi/content/abstract/31/11/1791

Surve, N. N. \& Bagde, U. S. (2009). Silver toxicity in pathogenic Staphylococcus epidermidis and Klebsiella pneumoniae. International Journal of Integrative Biology, 7(3): 139-144.

Surve, N. N. \& Bagde, U. S. (2010a). Arsenic toxicity in pathogenic Staphylococcus epidermidis and Klebsiella pneumoniae. International Journal of Biology, 2(2): 213-221.

Surve, N. N., \& Bagde, U. S. (2010b). Morphological alterations by methicillin on cell wall of Streptococcus agalactiae. International Journal of Integrative Biology, 11(1): 26-29. http://ijib.classicrus.com/trns/289801309233424.pdf 
Swaney, S. M., Aoki, H., Ganoza, M. C., \& Shinabarger, D. L. (1998). The oxazolidinone linezolid inhibits initiation of protein synthesis in bacteria. Antimicrob. Agents Chemother., 42(12): 3251-3255. http://aac.asm.org/cgi/content/abstract/42/12/3251

Troxler, R., von Graevenitz, A., Funke, G., Wiedemann, B., \& Stock, I. (2000). Natural antibiotic susceptibility of Listeria species: L.grayi, L. innocua, L. ivanovii, L. monocytogenes, L. seeligeri, and L. welshimeri strains. Clin. Microbiol. Infect., 6: 525-535. http://dx.doi.org/10.1046/j.1469-0691.2000.00168.x

Vazquez-Boland, J. A., Kuhn, M., Berche, P., Chakraborty, T., Dominguez-Bernel, G., Goebel, W., et al. (2001). Listeria pathogenesis and molecular virulence determinants. Clin. Microbiol. Rev., 14: 584-640. http://dx.doi.org/10.1128/CMR.14.3.584-640.2001

Venugopal, N. B., \& Reddy, S. L. N. (1992). Nephrotoxic and hepatotoxic effects of trivalent and hexavalent chromium in a teleost fish Anabes scandens, enzymological and biochemical changes. Ecotoxicol Environ SAF, 24(3): 287-293. http://dx.doi.org/10.1016/0147-6513(92)90004-M

Zurenko, G. E., Yagi, B. H., Schaadt, R. D., Allison, J. W., Kilburn, J. O., Glickman, S. E., et al. (1996). In vitro activities of U-100592 and U-100766, novel oxazolidinone antibacterial agents. Antimicrob. Agents Chemother., 40(4): 839-845. http://aac.asm.org/cgi/content/abstract/40/4/839

Table 1. Effect of Linezolid on the activity of dehydrogenases of Listeria ivanovii

\begin{tabular}{cccccccc}
\hline & \multicolumn{3}{c}{ Control } & \multicolumn{3}{c}{ Activity with Linezolid } \\
\hline Dehydrogenases enzymes & O.D. & Activity \% & Inhibition \% & O.D. & $\begin{array}{c}\text { Activity } \\
(\%)\end{array}$ & $\begin{array}{c}\text { Inhibition } \\
(\%)\end{array}$ \\
\hline Glutamic & 0.17 & 100 & 0 & 0.06 & 35 & 65 \\
Succinic & 0.16 & 100 & 0 & 0.08 & 50 & 50 \\
$\alpha$ Ketoglutaric & 0.26 & 100 & 0 & 0.08 & 31 & 69 \\
Isocitric & 0.16 & 100 & 0 & 0.06 & 38 & 62 \\
\hline
\end{tabular}

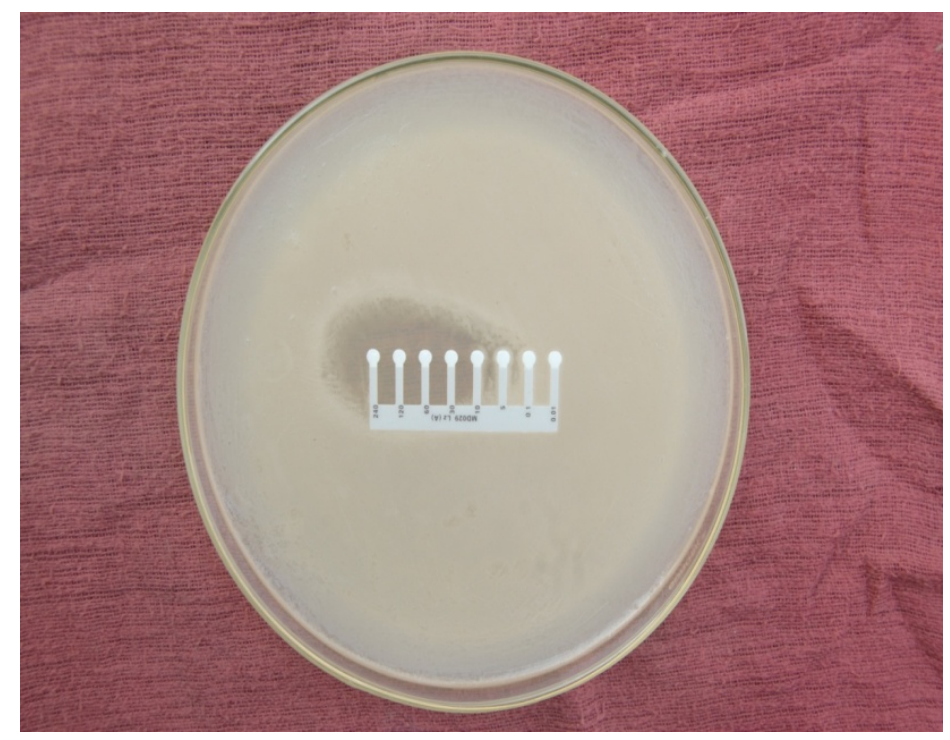

Figure 1. Determination of the MIC of Linezolid against L. ivanovii using Hi-Comb method. The clear area indicated the growth inhibition zone of the bacterium $(10 \mu \mathrm{g} / \mathrm{ml})$ 


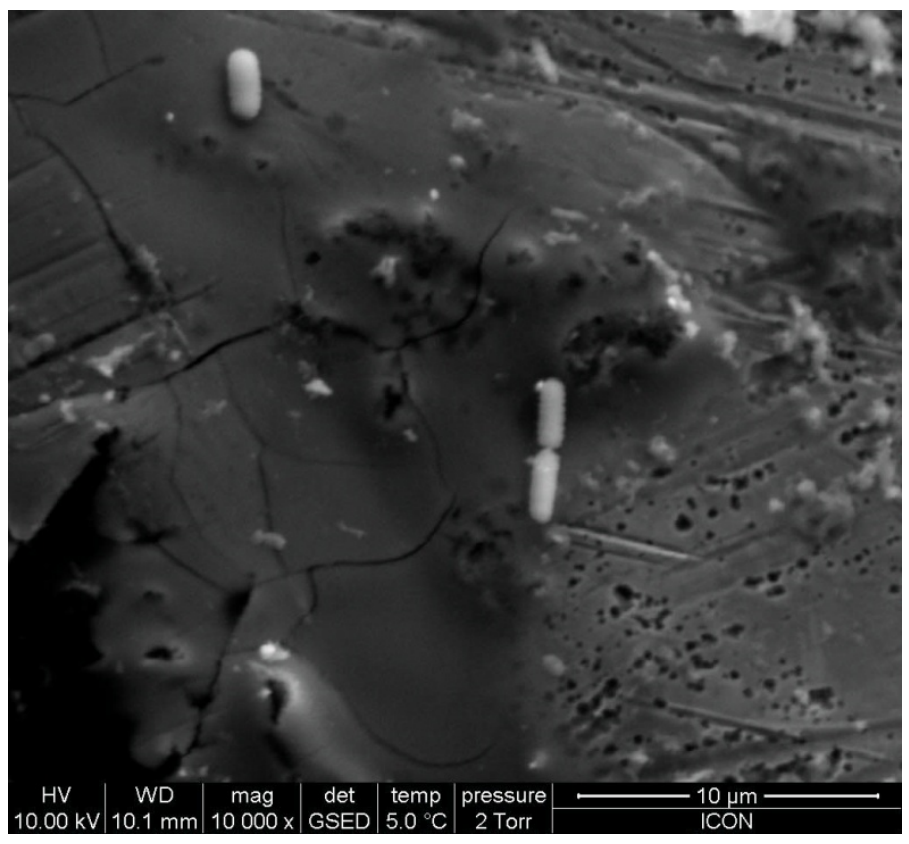

Figure 2. L. ivanovii under the untreated condition showing rod-shaped bacilli

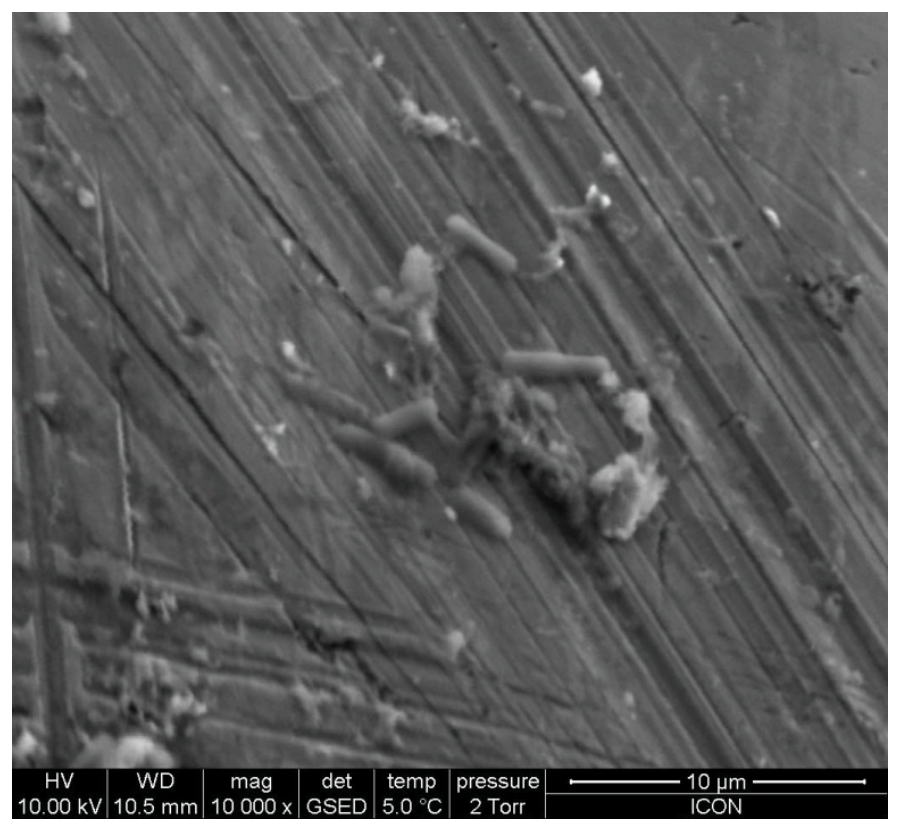

Figure 3a. L. ivanovii following treatment with Linezolid $(10 \mu \mathrm{g} / \mathrm{ml})$, exposed for $3 \mathrm{hrs}$ 


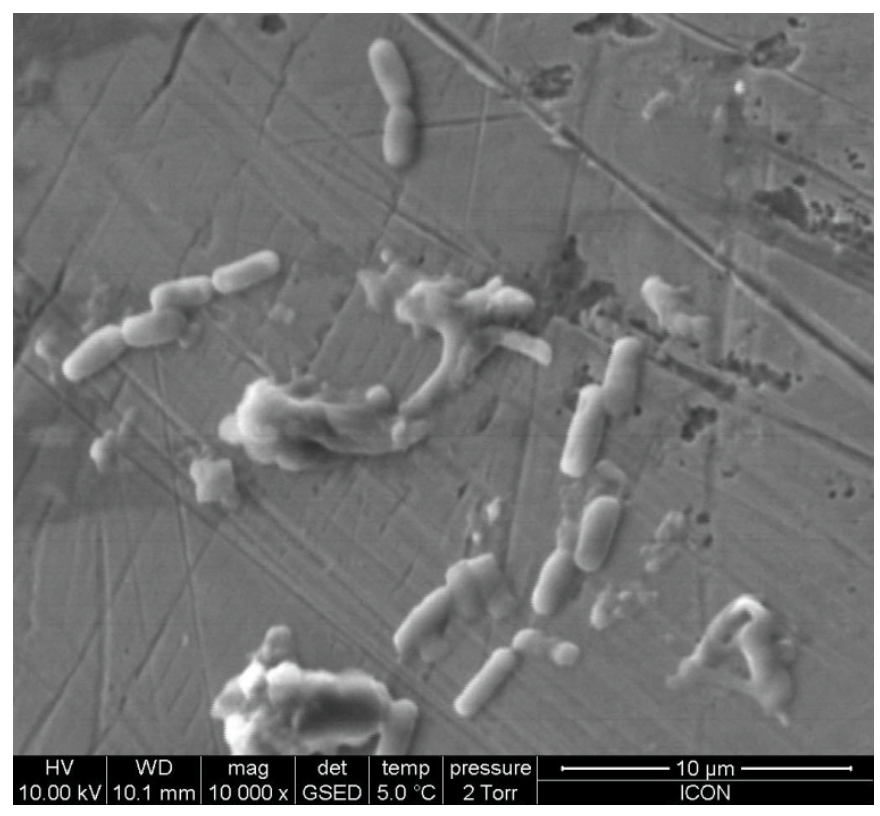

Figure 3b. L. ivanovii following treatment with Linezolid (10 $\mu \mathrm{g} / \mathrm{ml})$, exposed for $6 \mathrm{hrs}$

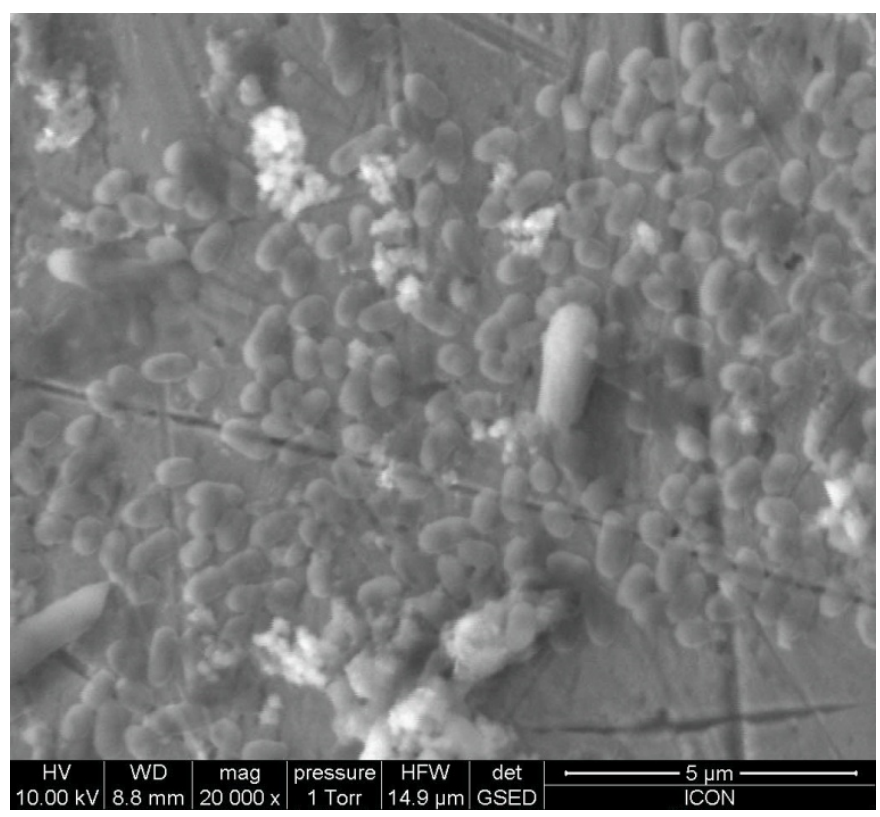

Figure 3c. L. ivanovii following treatment with Linezolid (10 $\mu \mathrm{g} / \mathrm{ml})$, exposed for $24 \mathrm{hrs}$ 